\title{
Acetylcholinesterase Inhibitors Assay Using Colorimetric pH Sensitive Strips and Image Analysis by a Smartphone
}

\author{
Adam Kostelnik, ${ }^{1,2}$ Alexander Cegan, ${ }^{1}$ and Miroslav Pohanka ${ }^{2,3}$ \\ ${ }^{1}$ Faculty of Chemical Technology, University of Pardubice, Studentska 95, 53210 Pardubice, Czech Republic \\ ${ }^{2}$ Faculty of Military Health Sciences, University of Defense, Trebesska 1575, 50001 Hradec Kralove, Czech Republic \\ ${ }^{3}$ Department of Geology and Pedology, Mendel University in Brno, Brno, Czech Republic \\ Correspondence should be addressed to Miroslav Pohanka; miroslav.pohanka@gmail.com
}

Received 29 September 2016; Accepted 17 January 2017; Published 13 February 2017

Academic Editor: Neil D. Danielson

Copyright (C) 2017 Adam Kostelnik et al. This is an open access article distributed under the Creative Commons Attribution License, which permits unrestricted use, distribution, and reproduction in any medium, provided the original work is properly cited.

\begin{abstract}
Smartphones are widely spread and their usage does not require any trained personnel. Recently, smartphones were successfully used in analytical chemistry as a simple detection tool in some applications. This paper focuses on immobilization of acetylcholinesterase (AChE) onto commercially available $\mathrm{pH}$ strips with stabilization in the gelatin membrane. AChE degrades acetylcholine into choline and acetic acid which causes color change of acid-base indicator. Smartphone served as a tool for measurement of indicator color change from red to orange while inhibitors blocked this process. AChE inhibitors were measured with limits of detection, $149 \mathrm{nM}$ and $22.3 \mathrm{nM}$ for galanthamine and donepezil, respectively. Organic solvents were measured for method interferences. Measurement procedure was performed on 3D printed holder and digital photography was evaluated using red-green-blue (RGB) channels. The invented assay was validated to the standard Ellman's test and verified on murine plasma samples spiked with inhibitors. We consider that the assay is fully suitable for practical performance.
\end{abstract}

\section{Introduction}

AChE is an enzyme splitting the neurotransmitter acetylcholine in cholinergic synapsis into choline and acetic acid [1]. Sensitivity of AChE to neurotoxic compounds (antiAlzheimer's drugs, pesticides, and nerve agents) can be use in their measurement [2]. Commonly used method is based on reaction of thiocholine, formed from acetylthiocholine during enzymatic hydrolysis, with Ellman's reagent producing yellow 5-thio-2-nitrobenzoate measurable by spectrophotometry in $412 \mathrm{~nm}$ [3]. Despite broad use, this method has some drawbacks like instability of Ellman's reagent and hemoglobin interference $[2,4,5]$. Furthermore, there is possibility of measuring enzyme activity electrochemically $[6,7]$. Colorimetric detection can be also based on $\mathrm{pH}$ measurement. Many acid-base indicators are known for this purpose, when phenol red was used in our work previously $[8,9]$. Different techniques for enzyme immobilization and matrix like gelatin were described as well [10-13]. Simple physical immobilization of enzyme onto cellulose and stabilization into gelatin matrix was successfully used for preparation of biosensor in an application where AChE was embedded into gelatin membrane on a paper matrix and performed for the assay of neurotoxic compounds $[14,15]$. In the cited papers, there was no, however, made evaluation of enzyme activity by a camera because a naked eye assay and another type of substrate were preferred. Gelatin provides good properties for enzyme immobilization combined with biocompatibility and zero toxicity [16]. Modern mobile phones dispose high resolution cameras which gives them ability to serve as a tool for diagnostics $[17,18]$. Previously mobile phones have been used for some applications in analytical chemistry $[19,20]$. This paper deals with preparation of biosensor based on commercial pH strips with immobilized AChE and stabilized in gelatin membrane. Performance of the biosensor was verified on neurotoxic compounds. This approach offers easy way for AChE inhibitors determination, especially if we considered well-established spectrophotometric assay; for the presented method here, no special equipment or trained personnel are required. There is also innovation in 
evaluation of color based reaction compared to previously described methods. The major advantage of our assay is based on the opportunity to link it to a smartphone which is considered as the detector device providing wide availability to less equipped laboratories and for field tests without any expensive gear.

\section{Material and Methods}

2.1. Materials and Devices. Acetylcholinesterase from electric eel ( $\geq 1000$ units/mg protein), acetylcholine chloride $(\mathrm{AChCl})$, acetylthiocholine chloride (ATChCl), 5, $5^{\prime}$-dithiobis(2-nitrobenzoic acid) (DTNB), donepezil hydrochloride monohydrate, galanthamine hydrobromide, tetraisopropyl pyrophosphoramide (iso-OMPA), phosphate buffer saline (PBS) pH 7.4, dimethyl sulfoxide (DMSO), and isopropyl alcohol were purchased from Sigma-Aldrich (St. Louis, MO, USA); denatured ethanol and gelatin were supplied by PENTA (Prague, Czech Republic). Indicator strips $\mathrm{pH}-$ Fix 6.0-7.7 were obtained from Macherey-Nagel (Düren, Germany). Color change was detected by Sony Xperia MT27i with $5 \mathrm{Mpx}$ camera and LED light using operation system Android 2.3.7., device version number 6.0.B.3.184 (Tokyo, Japan). For 3D print, 3D printer Prusa i3 from Prusa Research (Prague, Czech Republic) was used. Murine plasma samples were obtained from 20 female $\mathrm{BALB} / \mathrm{c}$ mice which were purchased from Velaz (Unetice, Czech Republic). The mice were kept under standard ambient temperature and humidity $50 \pm 10 \%$. Light and dark periods lasted equally for 12 hours each. The mice were sacrificed in the age of 8 weeks by cutting of carotid under carbon dioxide narcosis and the blood was taken into tubes pretreated with lithium heparin (Dialab, Prague, Czech Republic) and centrifuged at 1,000 ×g for 5 minutes. Fresh plasma was kept at $-80^{\circ} \mathrm{C}$ until use in the assay. The whole experiment was both permitted and supervised by ethical committee Faculty of Military Health Sciences (Hradec Kralove, Czech Republic).

2.2. Solutions Preparation. $\mathrm{AChCl}$ solutions were prepared in concentration range from 0.31 to $10 \mathrm{mM}$ and placed in microtubes. Galanthamine solutions were prepared in concentration range from 1.6 to $25.00 \mu \mathrm{M}$. Donepezil solutions were prepared in concentration range from 0.31 to $5.00 \mu \mathrm{M}$. Each solution was prepared in PBS 7.4 and final concentration in microtube was 10 times lower. Gelatin was prepared in $1 \%$ concentration by stirring of $10 \mathrm{mg}$ of gelatin in $1 \mathrm{ml}$ of water for $20 \mathrm{~min}$. All solutions for Ellman's assay were prepared in PBS 7.4. DTNB solution was prepared in concentration $1 \mathrm{mM}$ and $\mathrm{ATChCl}$ in $10 \mathrm{mM}$. Concentration range of galanthamine was from 62.5 to $100 \mu \mathrm{M}$ and 13 to $20 \mu \mathrm{M}$ in case of donepezil. Final concentrations in cuvette were 10 -fold less concentration of ATChCl and 40-fold less in case of galanthamine or donepezil. Iso-OMPA was prepared in PBS 7.4 in concentration $1 \mathrm{mM}$; final concentration in plasma samples was $0.1 \mathrm{mM}$.

2.3. Preparation of $p H$ Strips with AChE. To $\mathrm{pH}$ strips $10 \mu \mathrm{l}$ of AChE (activity for acetylthiocholine $1.73 \times 10^{-8} \mathrm{~mol} / \mathrm{s} / \mu \mathrm{l}$ ) was added and let to dry in laboratory temperature. Then
pH strips were covered by $10 \mu \mathrm{l}$ of $1 \%$ gelatin. After drying in laboratory temperature $\mathrm{pH}$ strips were stored in $4^{\circ} \mathrm{C}$ until used in the assay.

2.4. Preparation of $3 D$ Printed Holder. Holder was created in Autodesk 123D Design (open source software). 3D printer setup was as follows: acrylonitrile butadiene styrene shaped in $3 \mathrm{~mm}$ filaments was used as material, nozzle temperature was at $285^{\circ} \mathrm{C}$ and bottom temperature at $100^{\circ} \mathrm{C}$, and individual deposited layers were $0.1 \mathrm{~mm}$ thick. Size of holder was $80 \mathrm{~mm}$ in height and $105 \mathrm{~mm}$ in length and inner diameter of tube was set to $40 \mathrm{~mm}$ (Figure 1).

2.5. Smartphone Assay. The smartphone assay was made in the following way: $450 \mu \mathrm{l}$ of PBS pH 7.4 and $50 \mu \mathrm{l}$ of $10 \mathrm{mM}$ $\mathrm{AChCl}$ solution were added to microtubes and strip was put into it. After incubation of $15 \mathrm{~min}$, excess of reaction medium was drained and picture of the still wet $\mathrm{pH}$ strip was taken. During photographing, the camera was placed on the 3D printed holder and the strip inside; hence, no outer light influenced the photography and integrated LED light was the only one source. Distance between the strip and camera was also constant just due to the holder.

2.6. Ellman's Assay. To standard cuvette $400 \mu \mathrm{l}$ of DNTB solution, $25 \mu \mathrm{l}$ of AChE, $475 \mu \mathrm{l}$ of PBS, and $100 \mu \mathrm{l}$ of ATChCl were added. Absorbance was measured in $412 \mathrm{~nm}$ immediately and after incubation of $2 \mathrm{~min}$.

2.7. Data Processing. RGB color values were obtained by processing of photography in GIMP 2.8 .16 (open source software) using Color Picker function. $\Delta$ Color intensity was obtained as follows: intensity of strip before reaction - intensity of strip after the reaction. This difference corresponds to AChE activity in different concentration of used substrate or inhibitor. $K_{M}$ value for $\mathrm{AChE}$ and $\mathrm{AChCl}$ substrate was calculated using nonlinear curve fitting by Hill function with coefficient of cooperativity $n=1$. Limit of detection was calculated as signal to noise ratio equal to three. For these purposes, Origin software 8 PRO (OriginLab, Northampton, MA, USA) was used.

\section{Results and Discussion}

AChE splitting acetylcholine into choline and acetic acid resulted in decreasing $\mathrm{pH}$ of medium. Our method is based on color change of indicator in $\mathrm{pH}$ sensitive zone of $\mathrm{pH}$ strip from red to orange (Figure 2). During photography processing color change was observed in green channel while red and blue ones were without change.

3.1. Gelatin Optimization. Amount of gelatin was tested in $0 \%, 0.001 \%, 0.01 \%, 0.1 \%, 1 \%$, and $10 \%$ concentration. The strips were covered with $10 \mu$ l of gelatin in tested concentration and dipped into PBS 7.4 and color change of strip into red was observed after $5 \mathrm{~min}$. Gelatin in $10 \%$ concentration did not allow us to enter buffer to $\mathrm{pH}$ sensitive zone and color did not change into red one while it stayed orange which was represented by decreasing of color intensity (Figure 3). Color 


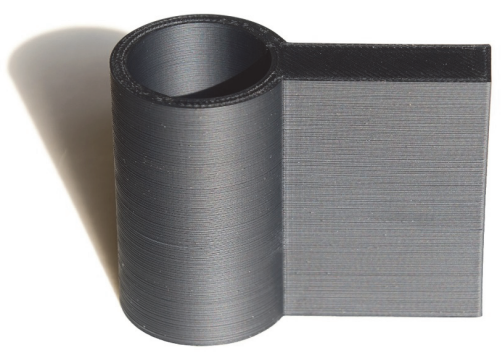

(a)

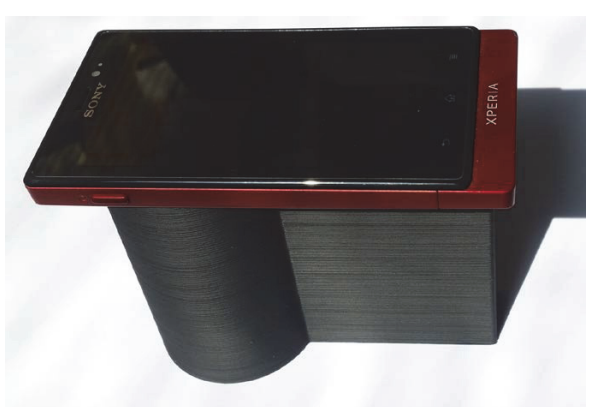

(b)

FIGURE 1: Tube shaped holder printed by 3D print technology (a) and the holder with a smartphone adjusted on the hole to provide photographs by an integrated camera.
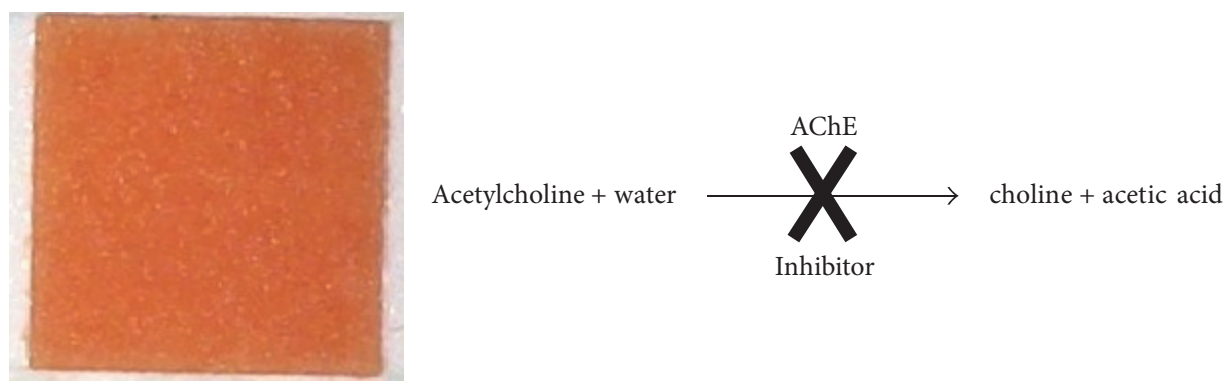

FIGURE 2: pH sensitive method using AChE principle.

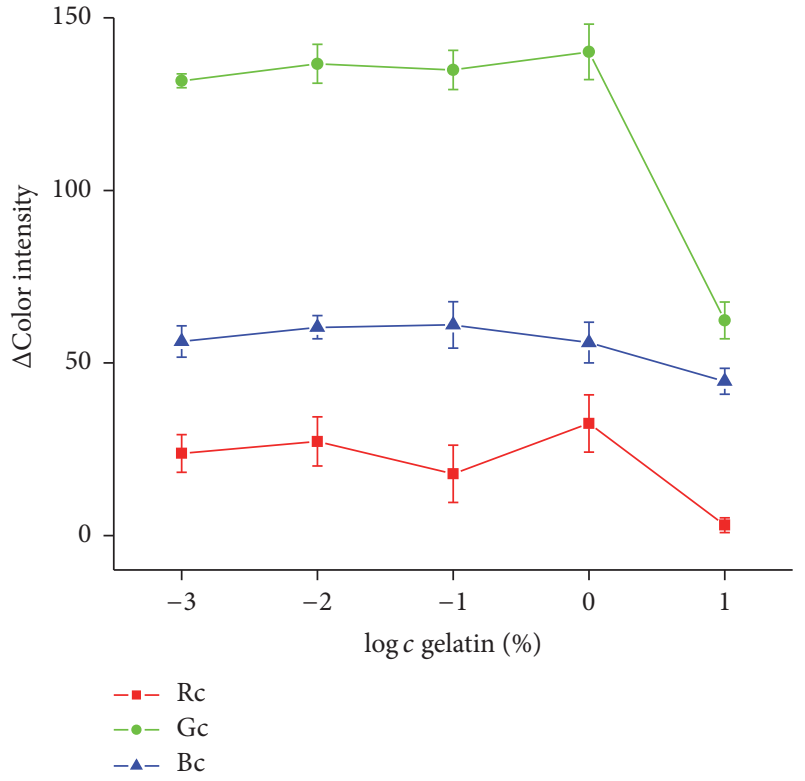

FIGURE 3: Gelatin optimization. Drop in $\Delta$ Color intensity indicates that $\mathrm{pH}$ strip did not change into red color. Error bars represent standard error of the mean for $n=3$. Rc $=$ red channel, $\mathrm{Gc}=$ green channel, and $\mathrm{Bc}=$ blue channel.

change into red was held while using gelatin in $1 \%$ and less concentration, but for further measurement $1 \%$ gelatin was chosen just for the better stabilization effect for AChE.

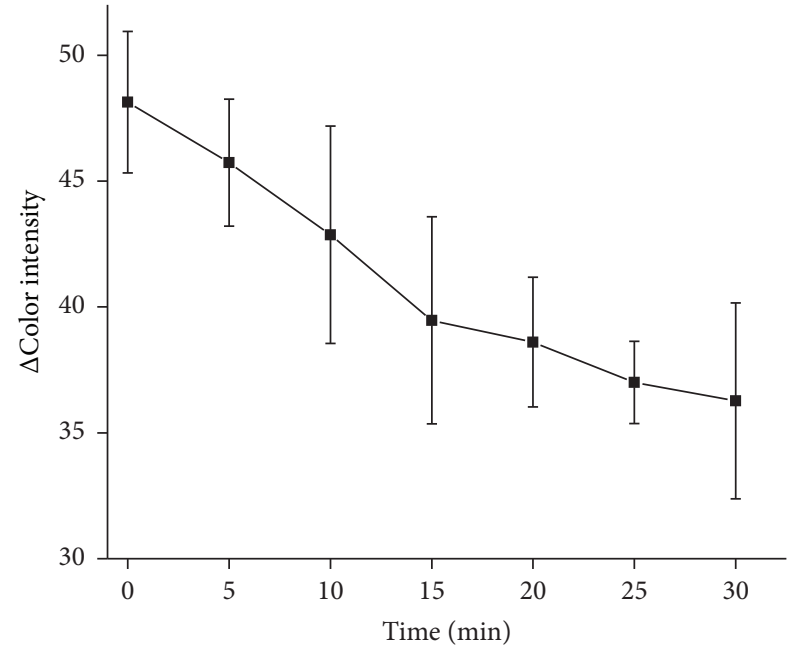

FIGURE 4: Optimization of $\mathrm{pH}$ strip incubation time with $\mathrm{ATChCl}$ as a substrate. Error bars represent standard error of the mean for $n$ $=3$.

3.2. Time Optimization. Strip with $\mathrm{AChE}$ and $1 \%$ gelatin was incubated with $1 \mathrm{mM} \mathrm{AChCl}$. Incubation time with $\mathrm{AChCl}$ was observed in $5 \mathrm{~min}$ intervals from 0 to $30 \mathrm{~min}$. The biggest color change was held up to $15 \mathrm{~min}$. Over this time color change was not significant for longer incubation time (Figure 4). 


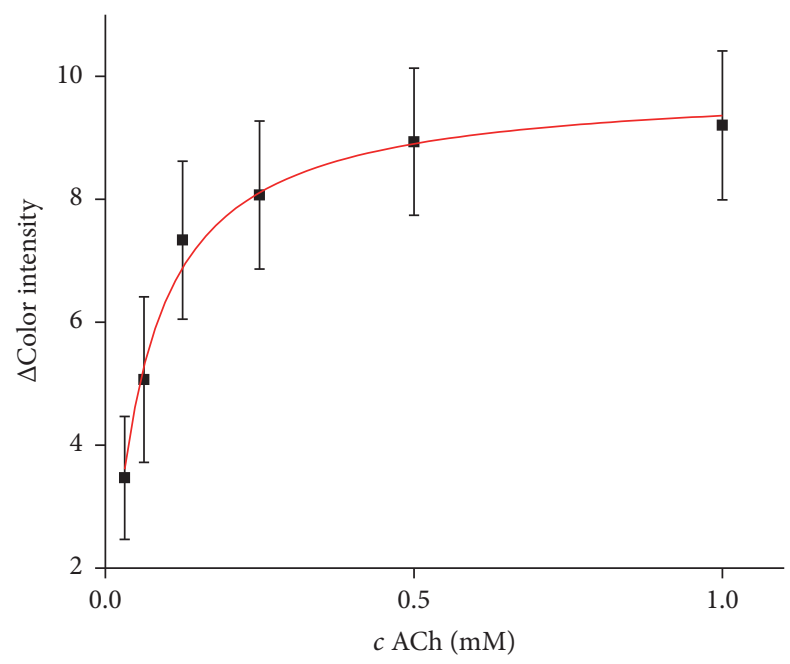

FIgURE 5: Saturation curve for AChE and $\mathrm{AChCl}$ as a substrate. Error bars represent standard error of the mean for $n=3$.

3.3. Substrate Measurement. Saturation curve for AChE and $\mathrm{AChCl}$ as a substrate was measured in concentration range from 0.031 to $1.0 \mathrm{mM}$ and $K_{M}$ value was calculated as described above to $54.26 \mu \mathrm{M}$ (Figure 5) while $73.9 \mu \mathrm{M}$ was reported by $\mathrm{Xu}$ and coworkers [24]. $K_{M}$ value however depends on type of used buffer as proved by Wille et al. using human AChE isolated from erythrocytes and achieved $K_{M}$ equal to $71.4 \mu \mathrm{M}$ in MOPS buffer, $98.2 \mu \mathrm{M}$ in PBS buffer, $0.1 \mathrm{mM}$ in Tyrode buffer, and $0.122 \mathrm{mM}$ in Tris buffer when $\mathrm{pH}$ was set to 7.4 [25]. There are also big differences between organisms as shown by Shaonan et al. who worked with AChE isolated from fish species and found out values above $0.1 \mathrm{mM}$ [26] and by Jiang et al. who reported $K_{M}$ to be $63.85 \mu \mathrm{M}$ when measured with mosquito AChE [27]. Recombinant enzymes exhibit slightly higher $K_{M}$ values compared to wild types as showed in experiments with mice AChE carried out by Boyd et al. who found out $K_{M}$ to be $46 \mu \mathrm{M}$ in wild type and $58 \mu \mathrm{M}$ for recombinant AChE [28].

3.4. Inhibitors Measurement. AChE is sensitive to neurotoxic compounds like drugs, nerve agents, or pesticides. Some of these compounds are widely used in treatment of Alzheimer disease [29]. Galantamine and donepezil can be examples for the currently available drugs [30]. We performed calibration curve of galanthamine in concentration range from 0.156 to $2.5 \mu \mathrm{M}$ with limit of detection calculated to $149 \mathrm{nM}$ and quantification limit of $0.5 \mu \mathrm{M}$ was achieved (Figure 6). Linearity of the assay is limited to $2.5 \mu \mathrm{M}$ when higher concentrations appeared to be indistinguishable. Comparing to the standard Ellman's assay, it is only 10 times higher detection limit, when $18.3 \mathrm{nM}$ of galanthamine was achieved in our experiment. From previously published methods for galanthamine measurement based on AChE inhibition we can conclude that our method is competitive [21, 22]. Although detection limits are similar, there is advantage in fabrication time of $\mathrm{pH}$ strip with immobilized AChE which is not time consuming.

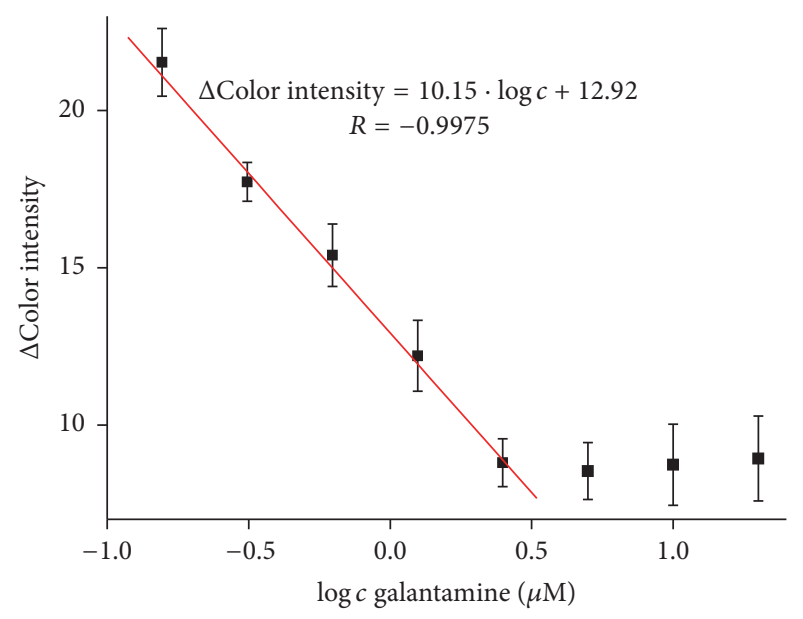

FIGURE 6: Calibration curve of galanthamine; concentration is given in logarithm. Error bars represent standard error of the mean for $n$ $=3$.

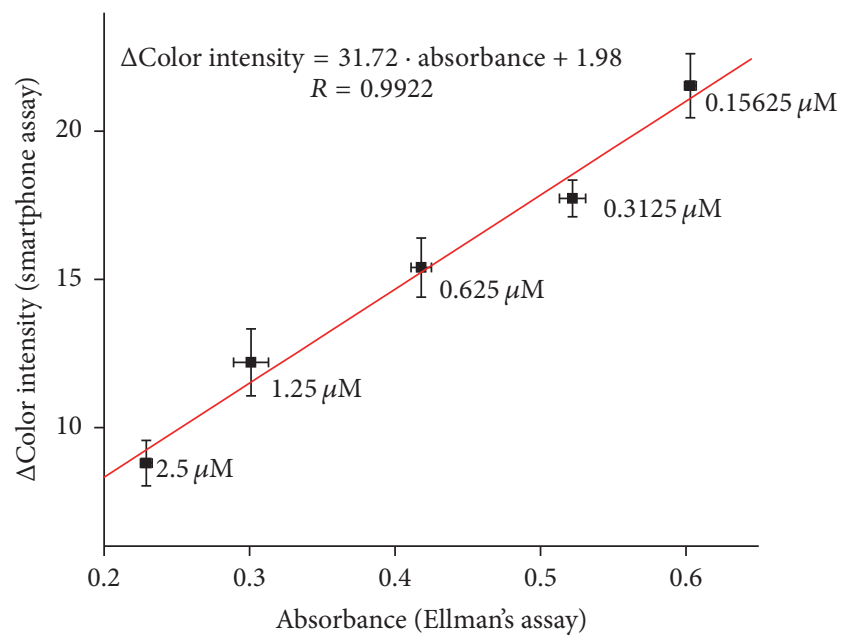

FIGURE 7: Validation of galanthamine assay compared to standard Ellman's assay. Error bars for smartphone assay represent standard error of the mean and for Ellman's assay standard deviation for $n=$ 3.

Validation of method for galanthamine measurement was done using standard Ellman's assay with correlation coefficient of 0.9922 (Figure 7).

Method was verified using murine plasma. Plasma samples were pretreated by iso-OMPA, selective inhibitor of butyrylcholinesterase [31], which naturally occurs in plasma and has ability to split acetylcholine. Then galanthamine was spiked into plasma samples in appropriate concentrations and smartphone assay has been performed (Figure 8). For measurement with plasma PBS buffer had to be replaced by water, because plasma strongly buffered itself; then PBS buffer was not required.

In literature, there are plenty of references about determination of donepezil by chromatography techniques $[32,33]$. Likewise, there are electrochemical methods for donepezil measurement with similar detection limits as our method [23, 


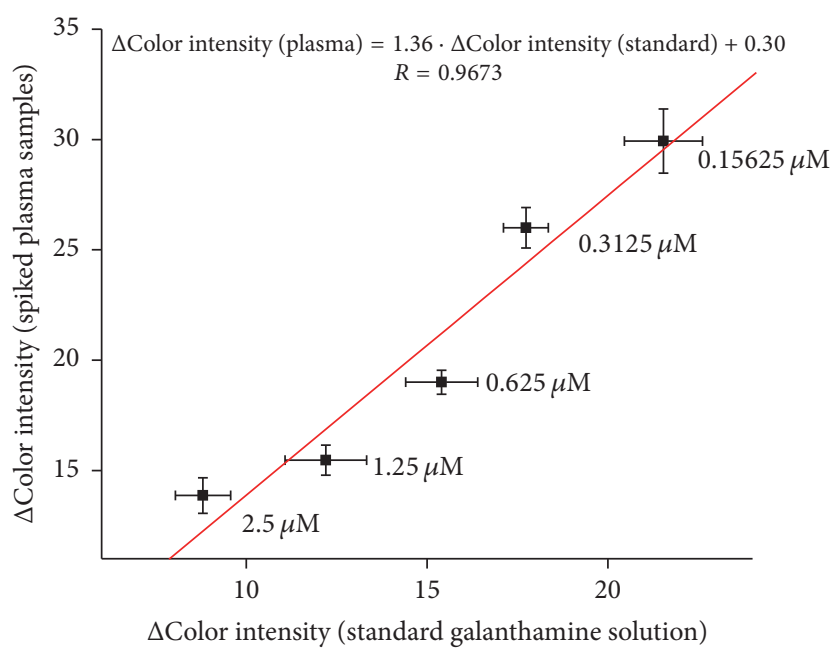

FIGURE 8: Verifying of galanthamine assay in plasma samples compared to standard galanthamine solution. Error bars represent standard error of the mean for $n=3$.

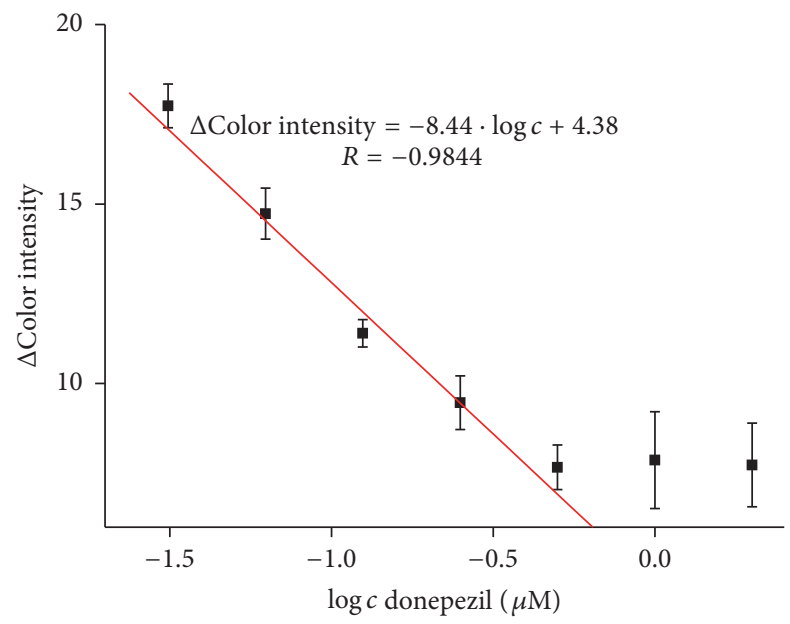

FIGURE 9: Calibration curve of donepezil; concentration is given in logarithm. Error bars represent standard error of the mean for $n=$ 3.

34] and some spectrophotometric methods for quantification of donepezil in pharmaceuticals or human plasma $[35,36]$. However, no evidence about determination of donepezil via inhibition of AChE was found. Donepezil calibration curve was done in concentration range from 0.031 to $0.50 \mu \mathrm{M}$ and limit of detection equal to $22.3 \mathrm{nM}$ was achieved while limit of quantification was found to be $0.2 \mu \mathrm{M}$ (Figure 9). Also, above calibration range there is limited linearity. For comparison, detection limit achieved by Ellman's assay in this experiment was equal to $3.82 \mathrm{nM}$.

Validation of method for donepezil measurement was performed using standard Ellman's assay with correlation coefficient equal to 0.9895 (Figure 10).

Verifying of donepezil in plasma samples was done as well. Donepezil was spiked in appropriate concentrations into pretreated plasma samples and smartphone assay was

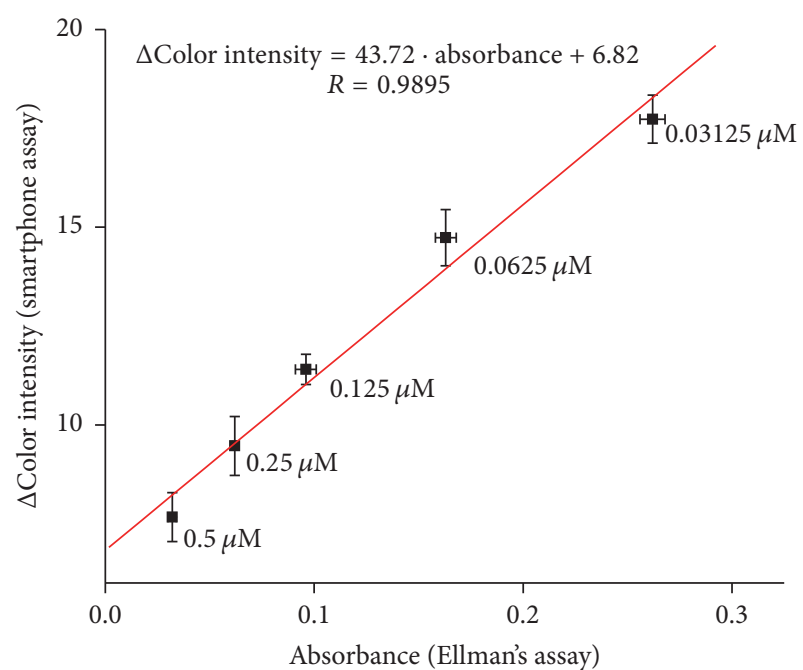

FIgURE 10: Validation of donepezil assay compared to standard Ellman's assay. Error bars for smartphone assay represent standard error of the mean and for Ellman's assay standard deviation for $n=$ 3.

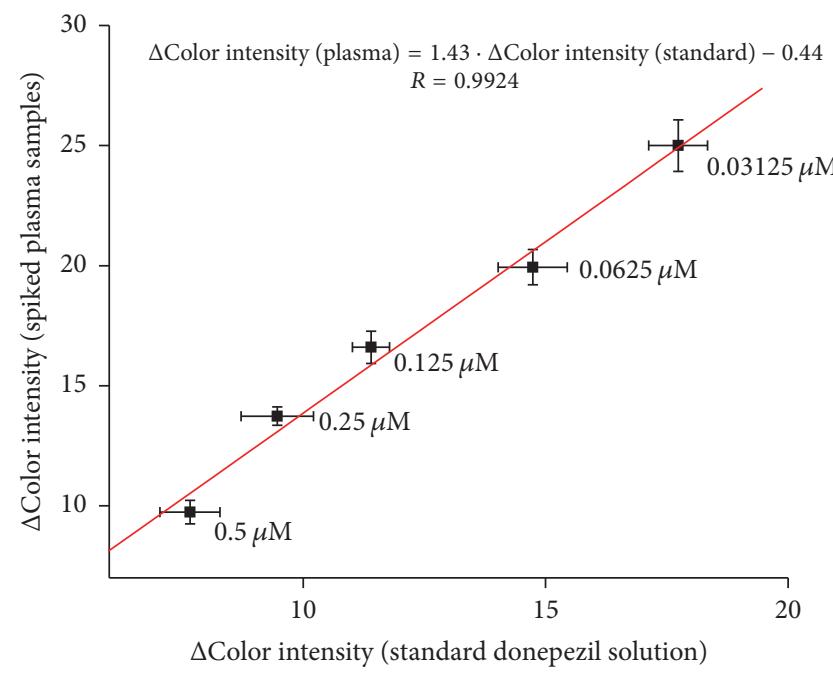

FIGURE 11: Verifying of donepezil assay in plasma samples compared to standard donepezil solution. Error bars represent standard error of the mean for $n=3$.

performed (Figure 11). PBS buffer was also replaced by water for reason mentioned in the principle based on $\mathrm{pH}$ change where a strong buffering could interfere. It appears that both measurements are in a good correlation.

3.5. Organic Solvents. Because AChE activity can be reduced by organic solvents in small concentration [37], we decided to consider them as possible interferents in the AChE based assay. For this purpose ethanol, isopropyl alcohol, and dimethyl sulfoxide were tested, all in 5\% concentration. Influence of DMSO to AChE activity has been investigated before and results showed that DMSO slightly decreases enzyme activity which was confirmed in our work [38]. 
TABLE 1: Comparison of presented assay with Ellman's assay and literature.

\begin{tabular}{|c|c|c|c|c|}
\hline & Detection limit & Fabrication time & Assay time & Necessary equipment \\
\hline $\begin{array}{l}\text { Presented smartphone } \\
\text { assay }\end{array}$ & $\begin{array}{l}\text { Galanthamine: } 149.1 \mathrm{nM} \\
\text { Donepezil: } 22.3 \mathrm{nM}\end{array}$ & Aprox. 1 hour & $15 \mathrm{~min}$ & Smartphone \\
\hline Standard Ellman's assay & $\begin{array}{l}\text { Galanthamine: } 18.3 \mathrm{nM} \\
\text { Donepezil: } 3.82 \mathrm{nM}\end{array}$ & NA & $10 \mathrm{~min}$ & Spectrophotometer \\
\hline $\begin{array}{l}\text { Spectrophotometric } \\
\text { assay [21] }\end{array}$ & Galanthamine: $0.05 \mathrm{nM}$ & Aprox. 3.5 hours & Aprox. 20 mn & Spectrophotometer \\
\hline $\begin{array}{l}\text { Potentiometric assay } \\
{[22]}\end{array}$ & Galanthamine: $5.4 \mathrm{nM}$ & Aprox. 10 hours & Aprox. $10 \mathrm{~min}$ & $\begin{array}{l}\text { Electrodes, } \\
\text { potentiometer }\end{array}$ \\
\hline $\begin{array}{l}\text { Square-wave } \\
\text { voltammetry [23] }\end{array}$ & Donepezil: $151 \mathrm{nM}$ & NA & Aprox. 20 min & $\begin{array}{l}\text { Electrodes, } \\
\text { electrochemical analyser }\end{array}$ \\
\hline
\end{tabular}

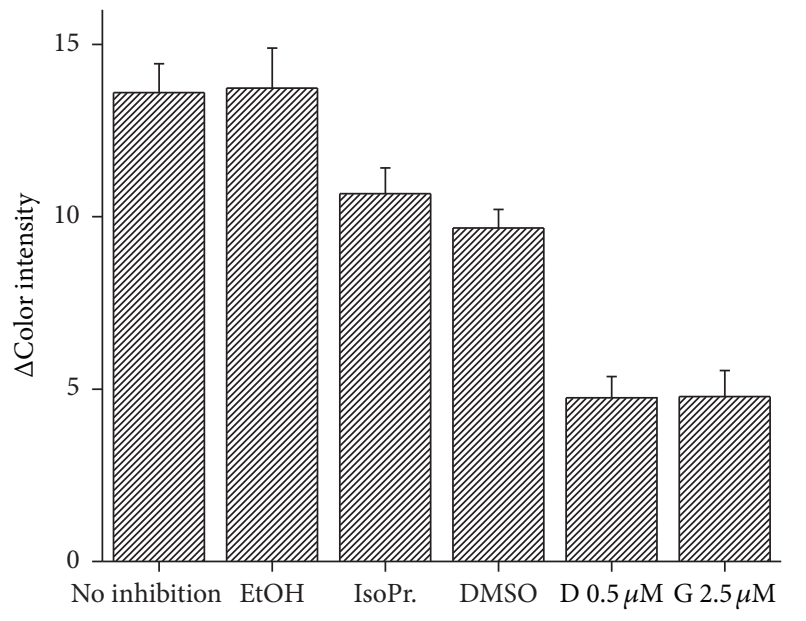

Figure 12: Method interferences by organic solvents. EtOH = ethanol, IsoPr. $=$ isopropyl alcohol, DMSO $=$ dimethyl sulfoxide, D $0.5 \mu \mathrm{M}=$ donepezil in $0.5 \mu \mathrm{M}$ concentration, and $\mathrm{G} 2.5 \mu \mathrm{M}$ $=$ galanthamine in $2.5 \mu \mathrm{M}$ concentration. Error bars represent standard error of the mean for $n=3$.

Ethanol has been reported to decrease AChE activity [37, 39]; however, there is evidence that at low concentration it can enhance enzyme activity $[38,40]$. No activity change against uninhibited enzyme was observed in our work. Isopropyl alcohol as well as ethanol can drop AChE activity [41] which is in agreement with our results. To compare used inhibitors, donepezil and galanthamine are included in graph (Figure 12).

\section{Conclusion}

Here, the presented method proved its ability for determination of neurotoxic compounds with promising limits of detection for galanthamine and donepezil, $149 \mathrm{nM}$ and $22.3 \mathrm{nM}$, respectively. Assay was successfully validated to the standard Ellman's spectrophotometric test and showed feasibility of measurement in plasma samples. Additionally, no specialized equipment and trained personnel are required; combined with low cost, portability, easy preparation, and miniaturization are considered as big advantages of the here invented method. Comparison of presented method with standard Ellman's assay and literature is given in Table 1.

\section{Competing Interests}

The authors declare that there is no conflict of interests with regard to the publication of this paper.

\section{Acknowledgments}

A Long-Term Organization Development Plan 1011 (Faculty of Military Health Sciences, University of Defense, Czech Republic) is gratefully acknowledged.

\section{References}

[1] M. Pohanka, "Cholinesterases, a target of pharmacology and toxicology," Biomedical Papers, vol. 155, no. 3, pp. 219-230, 2011.

[2] M. Pohanka, "Biosensors containing acetylcholinesterase and butyrylcholinesterase as recognition tools for detection of various compounds," Chemical Papers, vol. 69, no. 1, pp. 4-16, 2015.

[3] G. L. Ellman, K. D. Courtney, V. Andres Jr., and R. M. Featherstone, "A new and rapid colorimetric determination of acetylcholinesterase activity," Biochemical Pharmacology, vol. 7, no. 2, pp. 88-95, 1961.

[4] P. M. George and M. H. Abernethy, "Improved Ellman procedure for erythrocyte cholinesterase," Clinical Chemistry, vol. 29, no. 2, pp. 365-368, 1983.

[5] V. Gorun, I. Proinov, V. Băltescu, G. Balaban, and O. Bârzu, "Modified Ellman procedure for assay of cholinesterases in crude enzymatic preparations," Analytical Biochemistry, vol. 86, no. 1, pp. 324-326, 1978.

[6] M. Pohanka, "Voltammetric assay of butyrylcholinesterase in plasma samples and its comparison to the standard spectrophotometric test," Talanta, vol. 119, pp. 412-416, 2014.

[7] A. Kostelnik, A. Cegan, and M. Pohanka, "Electrochemical determination of activity of acetylcholinesterase immobilized on magnetic particles," International Journal of Electrochemical Science, vol. 11, no. 6, pp. 4840-4849, 2016.

[8] F. Morís-Varas, A. Shah, J. Aikens, N. P. Nadkarni, J. D. Rozzell, and D. C. Demirjian, "Visualization of enzyme-catalyzed reactions using $\mathrm{pH}$ indicators: rapid screening of hydrolase libraries and estimation of the enantioselectivity," Bioorganic and Medicinal Chemistry, vol. 7, no. 10, pp. 2183-2188, 1999. 
[9] A. Kostelnik, A. Cegan, and M. Pohanka, "Color change of phenol red by integrated smart phone camera as a tool for the determination of neurotoxic compounds," Sensors, vol. 16, no. 9, article 1212, 2016.

[10] S. Timur and A. Telefoncu, "Acetylcholinesterase (AChE) electrodes based on gelatin and chitosan matrices for the pesticide detection," Artificial Cells, Blood Substitutes, and Biotechnology, vol. 32, no. 3, pp. 427-442, 2004.

[11] J. Zhang, J. Zhang, F. Zhang et al., "Graphene oxide as a matrix for enzyme immobilization," Langmuir, vol. 26, no. 9, pp. 60836085, 2010.

[12] M. Mogharabi, N. Nassiri-Koopaei, M. Bozorgi-Koushalshahi, N. Nafissi-Varcheh, G. Bagherzadeh, and M. A. Faramarzi, "Immobilization of laccase in alginate-gelatin mixed gel and decolorization of synthetic dyes," Bioinorganic Chemistry and Applications, vol. 2012, Article ID 823830, 6 pages, 2012.

[13] R. A. Sheldon, "Enzyme immobilization: the quest for optimum performance," Advanced Synthesis and Catalysis, vol. 349, no. 89, pp. 1289-1307, 2007.

[14] M. Pohanka, "Cholinesterases in biorecognition and biosensors construction: a review," Analytical Letters, vol. 46, no. 12, pp. 1849-1868, 2013.

[15] M. Pohanka, "Acetylcholinesterase based dipsticks with indoxylacetate as a substrate for assay of organophosphates and carbamates," Analytical Letters, vol. 45, no. 4, pp. 367-374, 2012.

[16] Y. Zheng, Z. Liu, Y. Jing, J. Li, and H. Zhan, "An acetylcholinesterase biosensor based on ionic liquid functionalized graphene-gelatin-modified electrode for sensitive detection of pesticides," Sensors and Actuators, B: Chemical, vol. 210, pp. 389-397, 2015.

[17] K. Grudpan, S. D. Kolev, S. Lapanantnopakhun, I. D. McKelvie, and W. Wongwilai, "Applications of everyday IT and communications devices in modern analytical chemistry: a review," Talanta, vol. 136, pp. 84-94, 2015.

[18] A. García, M. M. Erenas, E. D. Marinetto et al., "Mobile phone platform as portable chemical analyzer," Sensors and Actuators, B: Chemical, vol. 156, no. 1, pp. 350-359, 2011.

[19] Y. Lu, W. Shi, J. Qin, and B. Lin, "Low cost, portable detection of gold nanoparticle-labeled microfluidic immunoassay with camera cell phone," Electrophoresis, vol. 30, no. 4, pp. 579-582, 2009.

[20] M. Pohanka, "Photography by cameras integrated in smartphones as a tool for analytical chemistry represented by an butyrylcholinesterase activity assay," Sensors, vol. 15, no. 6, pp. 13752-13762, 2015.

[21] B. J. White, J. A. Legako, and H. J. Harmon, "Spectrophotometric detection of cholinesterase inhibitors with an integrated acetyl-/butyrylcholinesterase surface," Sensors and Actuators, B: Chemical, vol. 89, no. 1-2, pp. 107-111, 2003.

[22] M. Cuartero, M. S. García, F. García-Cánovas, and J. Á. Ortuño, "New approach for the potentiometric-enzymatic assay of reversible- competitive enzyme inhibitors. Application to acetylcholinesterase inhibitor galantamine and its determination in pharmaceuticals and human urine," Talanta, vol. 110, pp. 8-14, 2013.

[23] A. Golcu and S. A. Ozkan, "Electroanalytical determination of donepezil $\mathrm{HCl}$ in tablets and human serum by differential pulse and osteryoung square wave voltammetry at a glassy carbon electrode," Pharmazie, vol. 61, no. 9, pp. 760-765, 2006.

[24] Z. Xu, S. Yao, Y. Wei et al., "Monitoring enzyme reaction and screening of inhibitors of acetylcholinesterase by quantitative matrix-assisted laser desorption/ionization fourier transform mass spectrometry," Journal of the American Society for Mass Spectrometry, vol. 19, no. 12, pp. 1849-1855, 2008.

[25] T. Wille, H. Thiermann, and F. Worek, "Effect of different buffers on kinetic properties of human acetylcholinesterase and the interaction with organophosphates and oximes," Archives of Toxicology, vol. 85, no. 3, pp. 193-198, 2011.

[26] L. Shaonan, X. Xianchuan, Z. Guonian, and T. Yajun, "Kinetic characters and resistance to inhibition of crude and purified brain acetylcholinesterase of three freshwater fishes by organophosphates," Aquatic Toxicology, vol. 68, no. 4, pp. 293299, 2004.

[27] H. Jiang, S. Liu, P. Zhao, and C. Pope, "Recombinant expression and biochemical characterization of the catalytic domain of acetylcholinesterase- 1 from the African malaria mosquito, Anopheles gambiae," Insect Biochemistry and Molecular Biology, vol. 39, no. 9, pp. 646-653, 2009.

[28] A. E. Boyd, A. B. Marnett, L. Wong, and P. Taylor, "Probing the active center gorge of acetylcholinesterase by fluorophores linked to substituted cysteines," The Journal of Biological Chemistry, vol. 275, no. 29, pp. 22401-22408, 2000.

[29] M. Pohanka, M. Hrabinova, J. Fusek et al., "Electrochemical biosensor based on acetylcholinesterase and indoxylacetate for assay of neurotoxic compounds represented by paraoxon," International Journal of Electrochemical Science, vol. 7, no. 1, pp. 50-57, 2012.

[30] J. I. da Silva, M. C. de Moraes, L. C. C. Vieira, A. G. Corrêa, Q. B. Cass, and C. L. Cardoso, "Acetylcholinesterase capillary enzyme reactor for screening and characterization of selective inhibitors," Journal of Pharmaceutical and Biomedical Analysis, vol. 73, pp. 44-52, 2013.

[31] D. R. Liston, J. A. Nielsen, A. Villalobos et al., "Pharmacology of selective acetylcholinesterase inhibitors: implications for use in Alzheimer's disease," European Journal of Pharmacology, vol. 486, no. 1, pp. 9-17, 2004.

[32] N. Yasui-Furukori, R. Furuya, T. Takahata, and T. Tateishi, "Determination of donepezil, an acetylcholinesterase inhibitor, in human plasma by high-performance liquid chromatography with ultraviolet absorbance detection," Journal of Chromatography B: Analytical Technologies in the Biomedical and Life Sciences, vol. 768, no. 2, pp. 261-265, 2002.

[33] C. Apostolou, Y. Dotsikas, C. Kousoulos, and Y. L. Loukas, "Quantitative determination of donepezil in human plasma by liquid chromatography/tandem mass spectrometry employing an automated liquid-liquid extraction based on 96-well format plates. Application to a bioequivalence study," Journal of Chromatography B, vol. 848, no. 2, pp. 239-244, 2007.

[34] E. M. Ghoneim, M. A. El-Attar, and M. M. Ghoneim, "Determination of donepezil hydrochloride in pharmaceutical formulation and human serum by square-wave adsorptive cathodic stripping voltammetry," Chemia Analityczna, vol. 54, no. 3, pp. 389-402, 2009.

[35] M. Yasir and U. Sara, "Development of UV spectrophotometric method for the analysis of acetylcholinesterase inhibitor," International Journal of Pharmacy and Pharmaceutical Sciences, vol. 6, no. 9, pp. 128-131, 2014.

[36] C. Patel, N. Patel, and C. Kothari, "Quantitative determination of donepezil hydrochloride by a simple and accurate synchronous spectrofluorimetric method in human plasma," Journal of Young Pharmacists, vol. 6, no. 4, pp. 47-50, 2014.

[37] M. Pohanka, J. Fusek, V. Adam, and R. Kizek, "Carbofuran assay using gelatin based biosensor with acetylcholinesterase as 
a recognition element," International Journal of Electrochemical Science, vol. 8, no. 1, pp. 71-79, 2013.

[38] T. Montesinos, S. Pérez-Munguia, F. Valdez, and J.-L. Marty, "Disposable cholinesterase biosensor for the detection of pesticides in water-miscible organic solvents," Analytica Chimica Acta, vol. 431, no. 2, pp. 231-237, 2001.

[39] S. Andreescu, T. Noguer, V. Magearu, and J.-L. Marty, "Screenprinted electrode based on ache for the detection of pesticides in presence of organic solvents," Talanta, vol. 57, no. 1, pp. 169176, 2002.

[40] S. Sook, W. Portia, and C. Chang-Hwei, "Biochemical studies of the actions of ethanol on acetylcholinesterase activity: ethnolenzyme-solvent interaction," International Journal of Biochemistry, vol. 23, no. 2, pp. 169-174, 1991.

[41] A. D. C. Obregon, M. R. C. Schetinger, M. M. Correa et al., "Effects per se of organic solvents in the cerebral acetylcholinesterase of rats," Neurochemical Research, vol. 30, no. 3, pp. 379-384, 2005. 

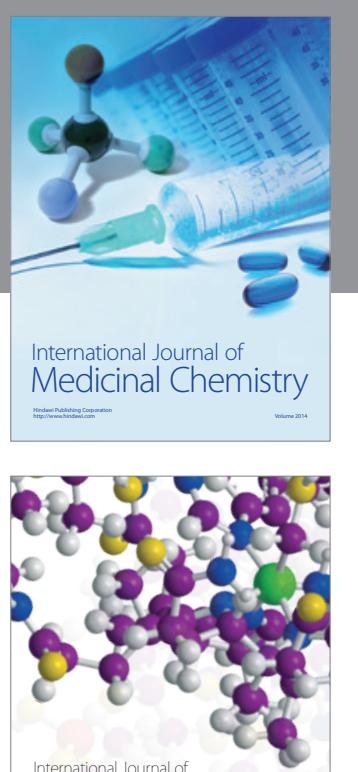

Carbohydrate Chemistry

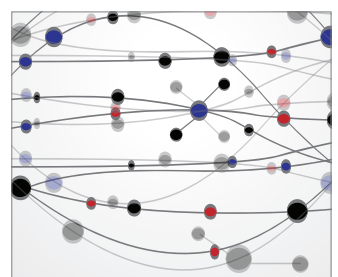

The Scientific World Journal
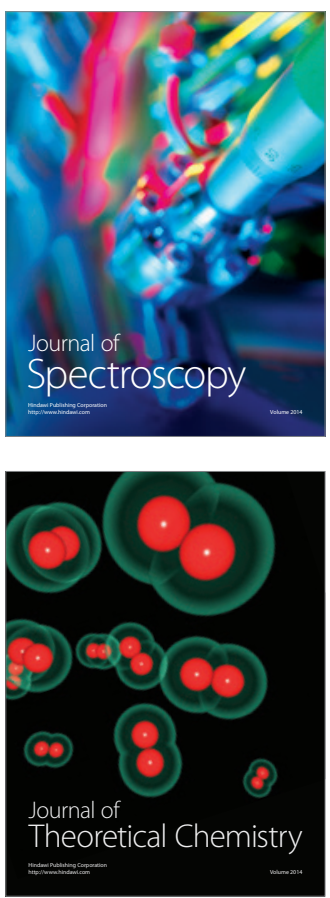
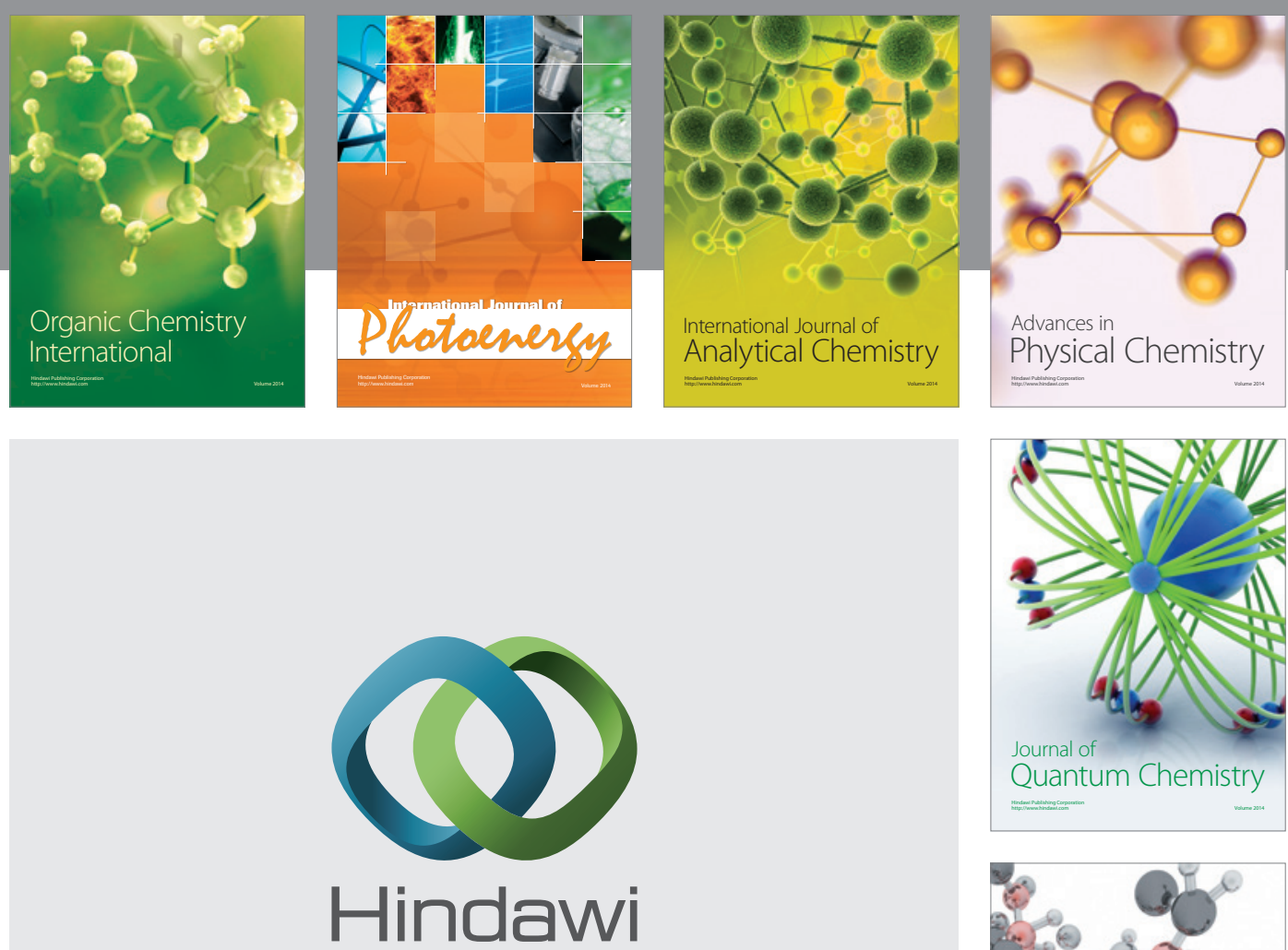

Submit your manuscripts at

https://www.hindawi.com

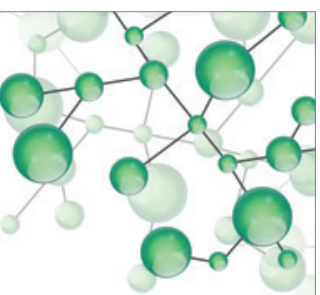

International Journal of

Inorganic Chemistry
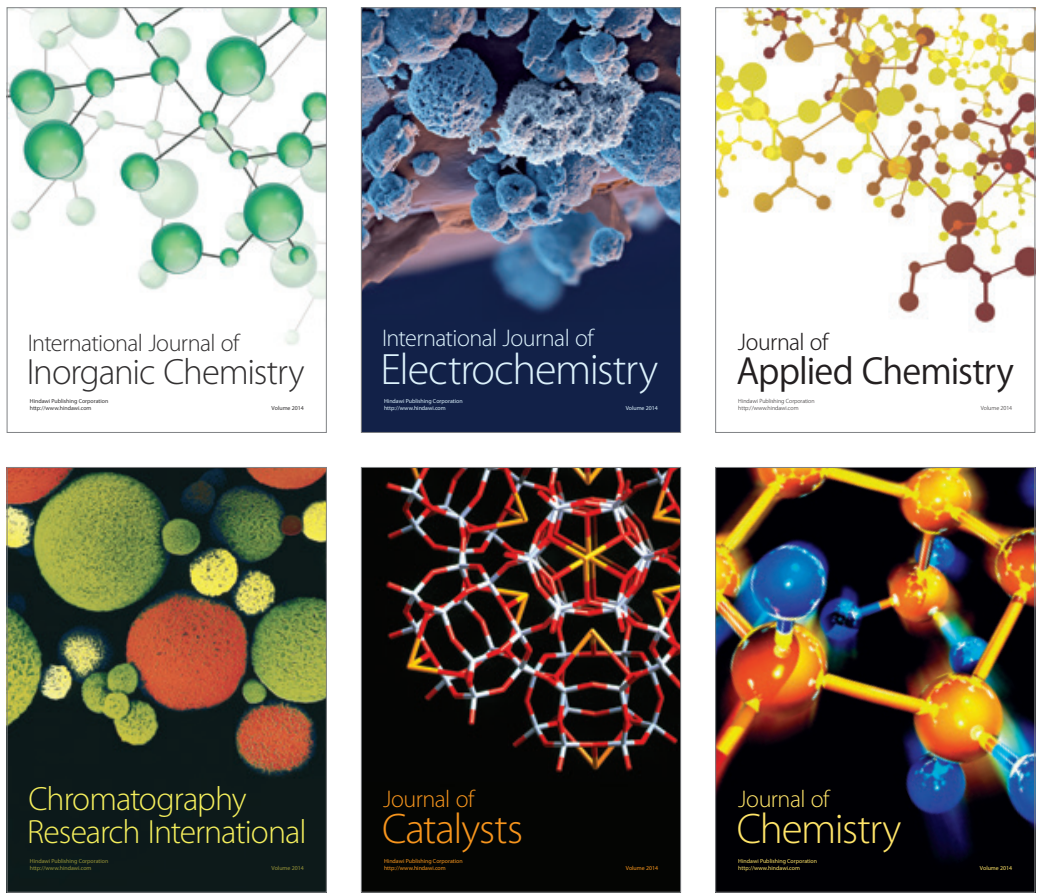

Journal of

Applied Chemistry
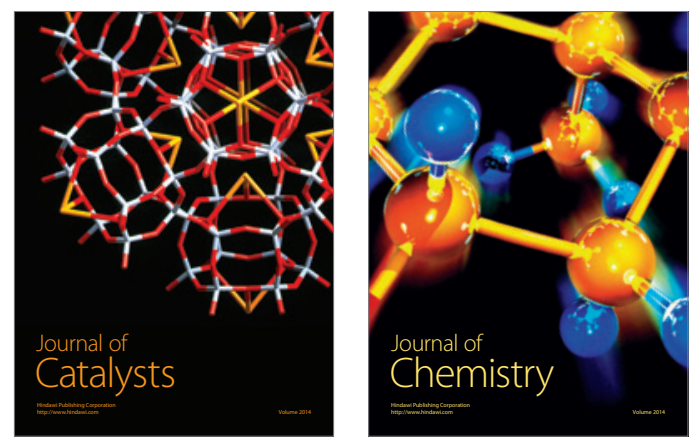
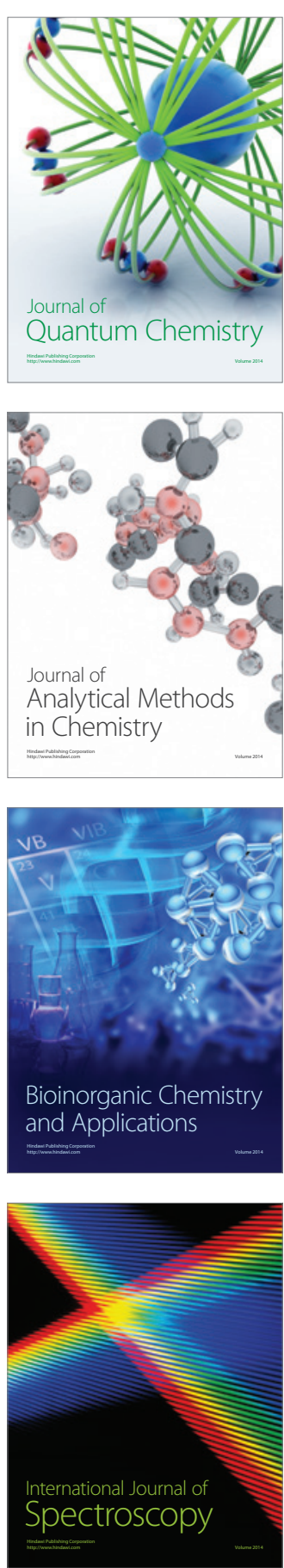